\title{
The Impacts of the Infectious Disease Epidemic on the Permanent Volatility of Precious Metal and Crude Oil Futures Markets: A Long-Term Perspective
}

\author{
Yue Shang $\mathbb{D}^{1},{ }^{1}$ Xiaodan Chen $\mathbb{D},{ }^{2}$ Yifeng Zhang $\mathbb{D},{ }^{2}$ and Yu Wei $\mathbb{i D}^{2}$ \\ ${ }^{1}$ School of Marxism, Yunnan University of Finance and Economics, Kunming, China \\ ${ }^{2}$ School of Finance, Yunnan University of Finance and Economics, Kunming, China \\ Correspondence should be addressed to Yu Wei; weiyusy@126.com
}

Received 31 July 2021; Revised 17 August 2021; Accepted 28 August 2021; Published 3 September 2021

Academic Editor: Dehua Shen

Copyright (c) 2021 Yue Shang et al. This is an open access article distributed under the Creative Commons Attribution License, which permits unrestricted use, distribution, and reproduction in any medium, provided the original work is properly cited.

The aim of this paper is to identify the quantitative impacts of the infectious disease pandemic on the permanent volatility of precious metal and crude oil futures from a long-term perspective by using a recently constructed Infectious Disease Equity Market Volatility Tracker (ID-EMV) to capture the epidemic severity and with a novel mixed data sampling GARCH (GARCHMIDAS) method. Different from the extant literature only focusing on the short-term influences of the COVID-19 epidemic on commodity futures market, this paper shows that the infectious disease pandemic does have significant and positive impacts on the permanent (long-term) volatilities of precious metal and crude oil futures markets lasting for at least up to 12 months. In addition, these specific impacts on crude oil futures are greater than those on precious metal futures. Finally, we find that the infectious disease epidemic has larger impacts on gold (WTI oil) futures than those on silver (Brent oil) futures. All these findings are robust after controlling the negative influences of lagged long-run realized volatility in commodity futures markets.

\section{Introduction}

The outbreak of COVID-19 has caused huge losses in the global real economy and financial markets, especially in the commodity futures markets due to its direct impacts on both the demand and supply chain of commodities [1-17]. Crude oil markets are hit the hardest for the collapse in travelling and massive plant shutdowns arising from mitigation measures [7, 11, 14, 16, 18-21]. On 20 April 2020, the NYMEX WTI crude oil futures settled at -37.63 USD, not only the biggest drop in history but also the first time for crude oil futures price falling below zero value. Accompanied with the plunge in oil prices, however, precious metal prices keep on an upward trend in general during the COVID-19 pandemic. For example, the COMEX gold futures price increases from near 1500 USD per ounce in January 2020 to about 1900 USD per ounce at the end of 2020 and reaches the highest price over 2000 USD in August 2020. Thus, precious metals are largely used as hedge assets against market risk in crude oil markets [18, 20, 22-25]. Although the hedging role of precious metals in crude oil assets have been widely discussed in the literature, no research focuses on the quantitative impacts of the infectious disease epidemic on the volatility, especially the permanent volatility, of precious metal and crude oil futures market from a long-term perspective. To the best knowledge of the authors, this paper is the first research focusing on the quantitative impacts of the infectious disease pandemic on the permanent volatility of precious metal and crude oil futures markets by using a recently invented Infectious Disease Equity Market Volatility Tracker (ID-EMV) to capture the epidemic severity and with a long-term data sample through 2010 to 2020 .

Most related research in investigating the influence of the infectious disease pandemic on precious metal and crude oil markets arose in the recent COVID-19 epidemic $[7,18,20,21]$. That means most of these studies focus on the short-term effects of COVID-19 on those commodity 
markets only by comparing the qualitative changes in market statuses (i.e., returns, volatilities, or correlations) before and after the outbreak of the COVID-19 epidemic. For example, Adekoya et al. [18] explored the hedging abilities of gold against oil and stock markets risks during the COVID-19 epidemic period by using the dynamic and regime dependent models. They found that gold can offset against oil and stock market risks across the times of global emergency, and short-term investors hoping portfolio diversification can find good hedging capability in gold. Dutta et al. [19] examined the safe-haven property of gold for crude oil market during the COVID-19 outbreak, and they showed that gold outperforms Bitcoin as a safe-haven asset. Mensi et al. [20] examined the impacts of COVID-19 on the asymmetric multifractality of gold and oil. They revealed that, in the pre-COVID-19 time period, the gold and oil markets are talentless in downward and upward trends, respectively. But, after the COVID-19 epidemic outbreak, gold and oil are even more talentless in upward and downward trends, respectively. Gold and oil have become more inefficient during the pandemic outbreak compared to the pre-COVID-19 period. Salisu et al. [21] evaluated the safe haven potential of gold vs. oil price risk by the asymmetric VARMA-GARCH model by using daily-frequency data. They found that gold presents major safe-haven characteristics to oil price risks. Corbet et al. [5] showed that the volatility connections among the Chinese stock markets, gold, oil and Bitcoin evolve significantly during this COVID19 period. Such time-varying dependences at the periods of stress show further fact to deliberately support the effectiveness of the development of Bitcoin. In addition, before the COVID-19 pandemic, there also has been plenty of research in exploring the return and volatility dependencies among precious metal and crude oil markets by using various econometric models [26-49]. For instance, AlYahyaee et al. [27] examined the multiscale associated movement and connectedness among precious and nonferrous metals by employing Diebold and Yilmaz's [50] spillover index and some wavelet approaches. They found strong comovements among nonferrous and precious metals across medium-term and low frequencies, and gold can offer the best diversification effect on nonferrous metals.

Although a great deal of work has been carried out in the field of volatility modelling for precious metal and crude oil markets [51-53], it is worth noting that no research has been conducted to test the direct impacts of the infectious disease epidemic on the long-term or permanent volatility of both precious metal and crude oil futures market by now. Furthermore, we think it is extremely important for policy makers, commodity producers, and investors to know the quantitative influences of infectious disease epidemic on long-run volatility in these commodity markets. In addition, identifying the differences in these influences between precious metal and crude oil assets can also help us to get deeper understanding in the heterogeneity among risky and hedging instruments when facing the same risk resources and then contribute to make better regulation measures and portfolio decisions [29, 37, 38, 40]. Therefore, this paper contributes to the extant literature in the three ways: firstly, instead of comparing the qualitative changes in returns, volatilities, or correlations in precious metal and crude oil futures markets during the recent COVID-19 pandemic, this paper focuses on the quantitative impacts of the infectious disease epidemic on the volatilities of precious metal and crude oil futures markets. There is no doubt that quantitative information of such impacts can help a lot for policy makers and investors in their decision-making processes. Secondly, most of recent related research is only interested in the short-term effects of the COVID-19 pandemic on commodity futures markets, e.g., a few months before and after the outbreak of COVID-19. This paper, however, explores the long-term influence of the infectious disease epidemic by using a data sample through January 2000 to November 2020, which can offer us more general pictures about the shocks of public health emergencies on volatilities of precious metal and crude oil futures markets. Finally, this paper provides marginal information about the impacts of infectious disease epidemic on the long-run (i.e., monthly) volatility of precious metal and crude oil markets by utilizing a new mixed data sampling GARCH model, i.e., GARCHMIDAS, proposed by Engle and Rangel [54] and Engle et al. [55], while most extant research only care about the shortrun (i.e., daily) volatilities in commodity markets during the COVID-19 turmoil by using ordinary GARCH-type or HAR-type models, while as pointed by Corsi [56], investors in financial markets are heterogeneous with different investment horizons, i.e., short, medium, and long run, for their different portfolio allocation purposes and structures.

The rest of this paper is organized as follows: Section 2 introduces the GARCH-MIDAS model, Section 3 provides descriptive statistics of the data, Section 4 discusses the empirical results, Section 5 presents some robustness checks of the major findings, and finally Section 6 concludes this paper.

\section{Methodology}

In traditional volatility modelling, GARCH-type models are commonly employed. However, these traditional models can only capture the impacts of exogenous variables on the volatility of endogenous variables with both of them sampling at the same time frequency, e.g., daily, weekly or monthly. In this paper, we aim at examining the impacts of the low-frequency infectious diseases epidemic (ID-EMV) on long-term volatility of precious metal and crude oil futures markets, which is out of the scope of those traditional GARCH-type models. Therefore, a novel mixed data sampling method (MIDAS), the GARCHMIDAS proposed by Engle and Rangel [54] and Engle et al. [55], is employed here to solve the problem of inconsistent sampling frequencies of exogenous and endogenous variables in volatility modelling. In the GARCH-MIDAS model, the conditional volatility of an asset is constructed by the product of a short-term volatility component and a long-term volatility one. To be specific, the short-term (e.g., daily) volatility element is caused by a simple GARCH $(1,1)$ process while the permanent (long-term) element is determined by a MIDAS regression on a low-frequency (e.g., monthly) exogenous variable. The concrete modelling process of the GARCHMIDAS model is as follows: 
In the GARCH-MIDAS model, the logarithmic return on day $i$ in month $t, r_{i, t}$, is calculated as

$$
\begin{gathered}
r_{i, t}-\omega=\sqrt{g_{i, t} \tau_{t}} z_{i, t}, \quad \forall i=1, \ldots, N_{t}, \\
z_{i, t} \mid I_{i-1, t} \sim N(0,1),
\end{gathered}
$$

where $\omega=E_{i-1, t}\left(r_{i, t}\right)$ is the conditional mean of $r_{i, t}$ given the information set, $I_{i-1, t}$, which is attainable at $(i-1)$ day in month $t$. $N_{t}$ is the total number of trading days in month $t$, and $z_{i, t}$ is an i.i.d. innovation term. Moreover, $g_{i, t}$ in equation (1) is the short-term volatility component following a $\operatorname{GARCH}(1,1)$ process as follows:

$$
g_{i, t}=(1-\alpha-\beta)+\alpha \frac{\left(r_{i-1, t}-\omega\right)^{2}}{\tau_{t}}+\beta g_{i-1, t},
$$

where $\alpha>0, \beta>0$ and $1-\alpha-\beta>0 . \tau_{t}$ in equation (1) is the permanent (long-term) volatility component. To keep it taking a positive value, we usually model the logarithmic $\tau_{t}$ by this MIDAS regression:

$$
\log \left(\tau_{t}\right)=m+\theta \sum_{k=1}^{K} \varphi_{k}(w) X_{t-k}
$$

where $K$ is the time lags for the permanent volatility and $X_{t-k}$ is a low-frequency exogenous impactor that may influence this permanent volatility; see, for example, monthly IDEMV utilized in this paper. $\varphi_{k}(w)$ is a weighting function to determine the decaying influence of $X_{t-k}$ and is defined by a one-parameter Beta polynomial:

$$
\varphi_{k}(w)=\frac{((1-k) / K)^{w-1}}{\sum_{j=1}^{K}((1-j) / K)^{w-1}},
$$

where $w \geq 1$. Furthermore, as pointed by Engle et al. [55], the permanent volatility is also easily impacted by its own past realized volatilities $R V_{t-k}$, which is defined as $R V_{t-k}=\sum_{i=1}^{N_{t}} r_{i, t-k}^{2}$ and thus we rewrite equation (3) to contain two low-frequency impactors as follows:

$$
\log \left(\tau_{t}\right)=m+\theta_{1} \sum_{k=1}^{K} \varphi_{k}\left(w_{1}\right) R V_{t-k}+\theta_{2} \sum_{k=1}^{K} \varphi_{k}\left(w_{2}\right) X_{t-k}
$$

where $R V_{t-k}$ can be treated as a control variable, which enables us to identify the quantitative influence of the lowfrequency exogenous variable $X_{t-k}$ on permanent volatility.

To estimate the GARCH-MIDAS model, two methods, fixed window and rolling window, are commonly employed. The difference between these two approaches is that the rolling-window method sets the long-run volatility to vary every high-frequency time; however, the fixed-window approach sets the permanent volatility in a calendar time window, i.e., one week/month/quarter/year. In the empirical analysis section, following the suggestions, we employ a rolling-window approach to identify the monthly factors in the empirical estimations. It means that the long-run or permanent volatility in this study can vary in each time period.

\section{Data}

In this empirical study, we use two categories of data sampling at daily and monthly frequencies, respectively. The first one is daily data of four commodity futures, i.e., precious metal and crude oil. To be specific, gold and silver futures traded in COMEX are utilized to represent the precious metal markets. In the same way, ICE Brent and NYMEX WTI crude oil futures are selected to indicate the performances of crude oil markets. All the daily futures prices are recorded for contracts at the earliest specified delivery date (for instance, for WTI crude oil, each contract expires on the third business day before the 25th calendar day of the month preceding the delivery month. If the 25 th calendar day of the month is a nonbusiness day, trading ceases on the third business day before the business day preceding the 25th calendar day. After a contract expires, the nearest expiration contract for the remainder of that calendar month is the second following month).

The second one is the monthly data of the Infectious Disease Equity Market Volatility Tracker (ID-EMV) developed by Baker et al. [57]. This ID-EMV tracker is constructed in the following steps: first, Baker et al. [57] specify related text terms in four sets as follows (term variants also included): (1) E: [economic, economy, and financial]; (2) M: [stock market, equity, equities, standard, and poor]; (3) V: [volatility, volatile, uncertain, uncertainty, risk, and risky] and (4) ID: [epidemic, pandemic, virus, flu, disease, coronavirus, MERS, SARS, EBOLA, H5N1, and H1N1]. Second, they obtain daily counts of newspaper articles that contain at least one term in each of E, M, V, and ID across approximately 3,000 US Newspapers. Third, the raw ID-EMV counts are scaled by the count of all articles in the same day. In a final step, they multiplicatively rescale the resulting series mirroring this approach to scale a Categorical EMV series in the overall EMV tracker. That is, they match the level of the VIX between 1990 and 2016 using the overall EMV index and then scale this ID-EMV index to reflect the ratio of the IDEMV articles to total EMV articles. Baker et al. [57] released the ID-EMV tracker at daily frequency in the website of Economic Policy Uncertainty (http://www. policyuncertainty.com), while we convert it into monthly frequency for the reason that there are many zero values of it at daily frequency. More specifically, there are 8240 zero records out of total 13118 (i.e., about 63\%) daily ID-EMV trackers through January 1, 1985 to November 30, 2020. Thus, it is difficult to track the quantitative fluctuations of the infectious diseases epidemic with this daily tracker containing too many zero values. Moreover, the major purpose of this research is to quantify the impact of the infectious disease epidemic on the long-term volatility of precious metal and crude oil markets. So, we transform daily ID-EMV ${ }_{i, t}$ at the $i$ th day in month $t$ into monthly ID$\mathrm{EMV}_{t}$ by summing all daily ID-EMV $i, t$ within a month $t$. The data sample used in this study goes through January 5 , 2000 to November 30, 2020, which is by far the longest research sample concerning impacts of ID-EMV on commodity futures market volatility as we know. The 
precious metal and crude oil futures price is available at the Wind database, and the ID-EMV data are collected from the website http://www.policyuncertainty.com/ infectious_EMV.html.

Figure 1 shows the time evolutions of returns for gold, silver, Brent, and WTI oil futures from January 2000 to November 2020. We can see that there is clear volatility clustering in these return series occasionally, e.g., during the time periods of the 2008 subprime mortgage crisis and the recent COVID-19 pandemic. Additionally, crude oil markets seem to fluctuate more violently than precious metal markets, especially during the recent COVID-19 pandemic time.

Table 1 presents the descriptive statistics of monthly IDEMV and four futures returns. Firstly, in general, for the reason of being recorded at different time frequencies, the monthly change rate of ID-EMV has larger mean and standard deviation than those of daily futures returns. In addition, ID-EMV has smaller skewness and kurtosis than futures returns and, thus, presents normal distribution. Secondly, in terms of commodity futures, Brent and WTI oil have larger standard deviations than gold and silver returns, indicating greater risk is observed in oil markets than in precious metal markets. This is also reasonable due to the facts that gold and silver are commonly used as hedging assets against risk assets, such as crude oil. Moreover, all the four commodity futures returns have negative skewness and kurtosis larger than 3, providing confirmative evidence of nonnormality distributions of them. Additionally, we can also see that gold and silver have no significant auto-correlations in the time series but Brent and WTI crude oil have, implying long-memory features in oil markets. Finally and most importantly, all the ADF and P-P tests reject the null hypothesis of unit root in these time series, indicating that all the return series are stationary and can be modelled without further transforms.

\section{Empirical Analysis}

In this section, we use the GARCH-MIDAS + ID-EMV method defined by equations (1)-(4) to quantify the impacts of infectious disease epidemic on permanent volatility of precious metal and crude oil markets. That means only one exogenous variable, i.e., monthly ID-EMV tracker, is incorporated in equation (3) and the parameter $\theta$ indicating the quantitative impacts is what we are most interested in.

We present in Figure 2 the estimated total and long-run (permanent) volatility of four futures assets with 6-month lags in ID-EMV. Firstly, it shows that, in most time periods, the total volatility fluctuates around permanent component, except for silver futures. Secondly, regarding precious futures markets, in the most volatile time periods, i.e., the 2008 global financial crisis and the recent COVID-19 pandemic, the long-run volatility increases accordingly in gold futures, while it seems to have no obvious ascents in silver futures. This finding implies that gold and silver futures may respond differently to common risk factors, especially in their long- run volatilities. Finally, in terms of crude oil futures, we find that the long-run volatility components in Brent and WTI oil react to risk factors in a high degree of consistency. Both of them increase moderately during the 2008 financial crisis but surging upwards in the recent COVID-19 epidemic.

Furthermore, to get more quantitative and robust results, we estimate the GARCH-MIDAS + ID-EMV models by setting time lags of ID-EMV through 3 to 12 months, which are presented in Tables 2-5, respectively. As we can see, Tables 2-5 show highly consistent estimation results. Firstly, almost all the estimated parameters are significant at the $1 \%$ level in both short- and long-run volatility models, indicating good fitness of the GARCH-MIDAS model with these commodity futures returns. Secondly, the parameters, $\alpha$ and $\beta$, for short-term volatility are all significant at the $1 \%$ level. In particular, all the $\beta$ parameters are larger than 0.91 , revealing strong volatility clustering features in these precious metal and crude oil futures markets. Finally, and most importantly, the estimate parameters $\theta$ are positive and significant at the $1 \%$ level across all the four futures with different time lags (from 3 to 12 months), implying that a severer infectious disease epidemic will result in greater long-run volatility in these commodity futures markets. This finding demonstrates that the infectious disease epidemic can really influence the permanent volatility in precious metal and crude oil market. Thus, it is a key factor that should be considered in volatility modelling and risk measurement for policy makers and investors.

More specific, except for the case of 6-month lags in IDEMV, we can find that ID-EMV has larger impacts (i.e., larger $\theta$ ) on the permanent volatility in crude oil markets than it does in precious metal markets, confirming the fact that crude oil is a risky asset while precious metal can be used to hedge this risk $[27,48,58]$. In addition, within precious metals, the impacts of ID-EMV on gold is greater than those on silver, proving that gold is easier than silver to be influenced by infectious disease epidemic, which is consistent with the conclusions in some extant research $[58,59]$. Similarly, in terms of crude oil futures, WTI oil is more likely to be affected by ID-EMV than Brent oil. The possible reasons for this finding are twofold: on the one hand, NYMEX WTI oil price is primarily used as the benchmark for pricing U.S. oil imports and local production in North America (including Canada). However, for the vast majority of the world's crude oil production areas, such as in the North Sea, Africa, Latin America, and some Middle and Far Eastern regions, ICE Brent oil price is usually used as the pricing benchmark. Thus, when facing the same risk factors, ICE Brent oil price can be more likely to diversify these shocks through its broader oil production regions, while WTI oil price is more susceptible to shocks of uncertainty than Brent oil for its relative limited production locations. On the other hand, the U.S. shale oil revolution, which began in 2005, has increased greatly the elasticity of U.S. crude oil production and, therefore, increased the volatility in WTI oil price. 

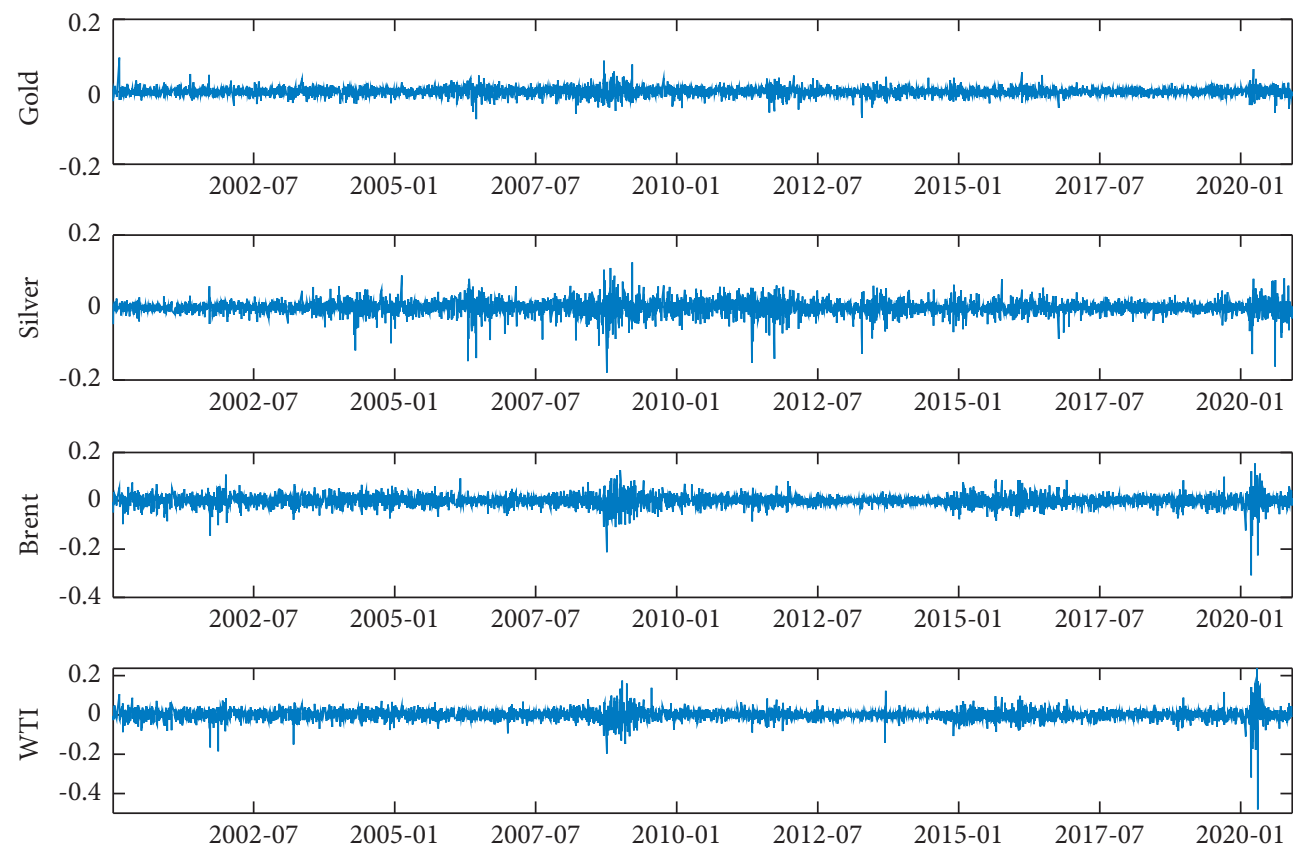

Figure 1: Time evolutions of returns for precious metal and crude oil futures.

TABLE 1: Descriptive statistics for ID-EMV and commodity futures returns.

\begin{tabular}{|c|c|c|c|c|c|}
\hline & ID-EMV & Gold & Silver & Brent & WTI \\
\hline Frequency & Monthly & Daily & Daily & Daily & Daily \\
\hline Mean (\%) & 1.327 & 0.037 & 0.031 & 0.015 & 0.012 \\
\hline Standard deviation (\%) & 66.143 & 1.107 & 1.955 & 2.327 & 2.656 \\
\hline Skewness & 0.146 & -0.023 & -0.912 & -0.784 & -1.548 \\
\hline Kurtosis & 0.523 & 8.640 & 11.985 & 15.666 & 35.259 \\
\hline Jarque-Bera & 3.771 & $6700.547^{* * *}$ & $17702.994^{* * *}$ & $34308.611^{* * *}$ & $221208.003^{* * *}$ \\
\hline$Q(5)$ & $51.601^{* * *}$ & 2.559 & 4.029 & $14.279^{* *}$ & $15.302^{* * *}$ \\
\hline$Q(10)$ & $57.327^{* * *}$ & $16.127^{*}$ & 9.911 & $21.541^{* *}$ & $23.993^{* * *}$ \\
\hline $\mathrm{ADF}$ & $-16.223^{* * *}$ & $-71.327^{* * *}$ & $-71.157^{* * *}$ & $-73.889^{* * *}$ & $-73.582^{* * *}$ \\
\hline P-P & $-28.514^{* * *}$ & $-71.402^{* * *}$ & $-71.168^{* * *}$ & $-73.885^{* * *}$ & $-73.577^{* * *}$ \\
\hline
\end{tabular}

Notes. The Jarque-Bera statistic tests for the null hypothesis of normality in sample returns distribution. $Q(n)$ is the Ljung-Box statistics of the return series for up to the $n$ th-order serial correlation. ADF and P-P are statistics of the Augmented Dickey-Fuller and Phillips-Perron unit root test based on the least AIC criterion, respectively. ${ }^{* * *},{ }^{* *}$, and ${ }^{*}$ indicate rejection at the $1 \%, 5 \%$, and $10 \%$ significance level, respectively.

\section{Robustness Checks}

In this section, we further employ GARCH-MIDAS models with two monthly exogenous variables to test the robustness of the major findings in Section 4. As stated by Engle et al. [55], the long-run volatility in financial markets is closely related by its past realized volatility $R V_{t-k}$. It means that the effects of other possible risk factors on futures permanent volatility, rather than infectious disease epidemic (ID-EMV), can be captured by its past realized volatility, as pointed by Bai et al. [60]. Thus, in this section, we use a model, labelled as GARCH-MIDAS + RV + IDEMV, defined in equation (5) to reestimate the empirical results reported in Tables $2-5$.

Figure 3 further presents the estimated total and longrun volatility of the four futures assets with 6-month lags in both RV and ID-EMV. It means that the observed permanent volatilities in Figure 3 are not determined by the sole impacts of ID-EMV but by the joint effects of lagged RV and the infectious disease epidemic. In general, Figure 3 looks consistent with Figure 2 with several slight differences. Firstly, it shows that the total volatility fluctuates around its permanent component, except for silver futures. Secondly, during periods of severe market disruptions, i.e., the 2008 financial crisis and the recent COVID-19 pandemic, the long-run volatility observed in gold and silver markets are similar to those in Figure 2. However, with respect to crude oil futures, we find quite different pictures in Figure 3. For instance, the permanent volatilities in crude oil markets decrease clearly rather than increase during the period of the 2008 global financial crisis, indicating that lagged RV can really suppress the increase in the present permanent 

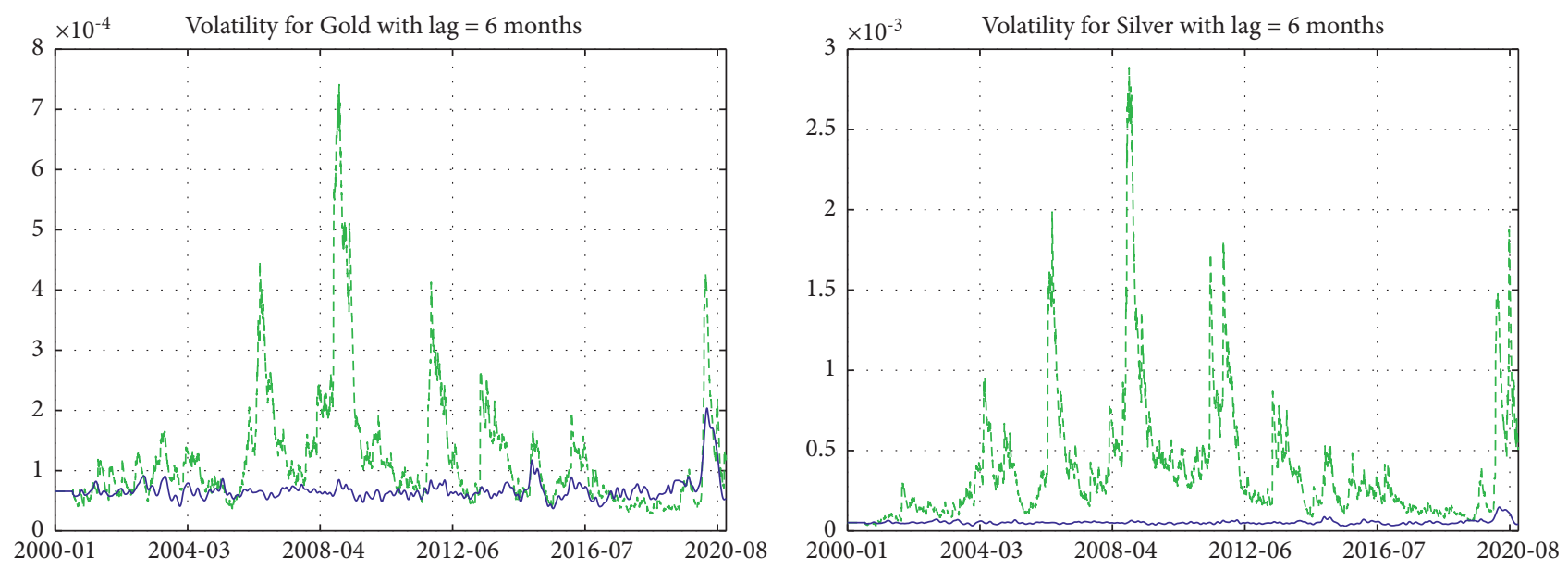

- - - Total volatility

— Long-run volatility

- - Total volatility

— Long-run volatility
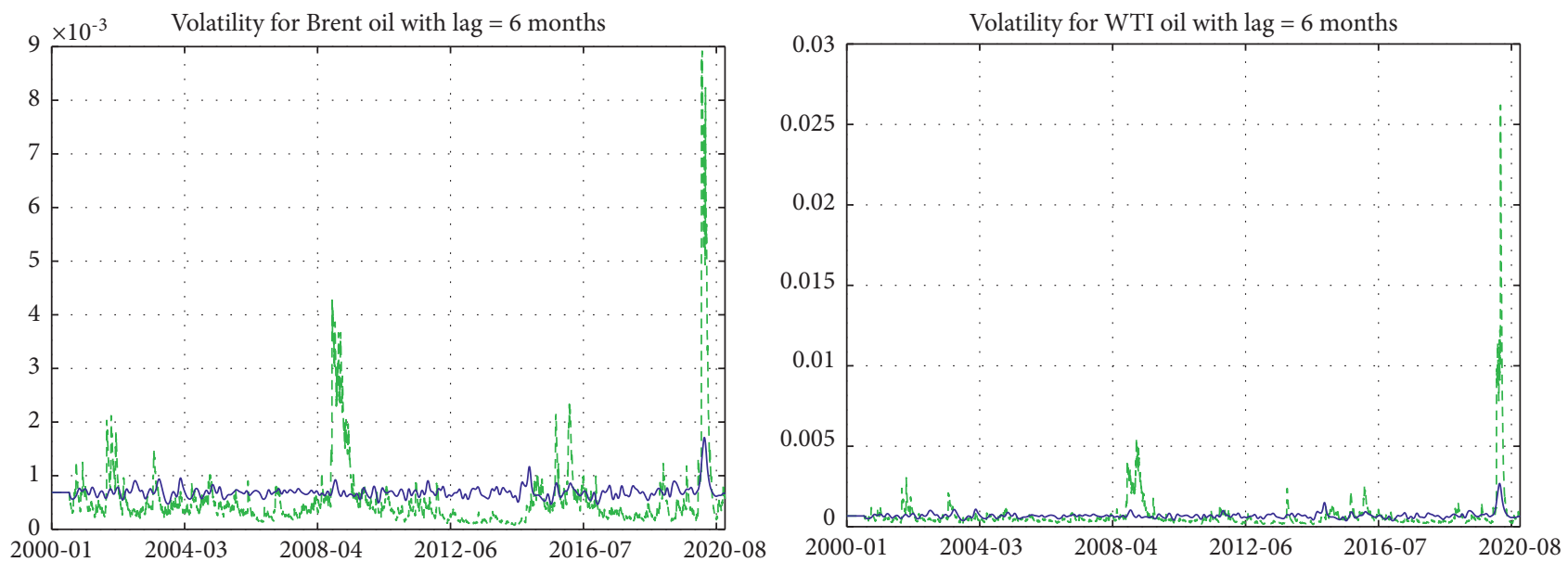

- - - Total volatility

— Long-run volatility

- - Total volatility

Long-run volatility

FIGURE 2: Estimated total and long-run volatility of precious metal and crude oil futures with GARCH-MIDAS + ID-EMV models.

TABLE 2: Estimation results of GARCH-MIDAS + ID-EMV models of futures volatility by infectious disease with 3-month lags.

\begin{tabular}{|c|c|c|c|c|c|c|c|}
\hline Futures & $\omega$ & $\alpha$ & $\beta$ & $m$ & $\theta$ & $w$ & $\log L$ \\
\hline Gold & $\begin{array}{l}0.0003^{* *} \\
(0.0001)\end{array}$ & $0.0281^{* * *}(0.0012)$ & $0.9718^{* * *}(0.0014)$ & $\begin{array}{c}-9.3882^{* * *} \\
(0.1696)\end{array}$ & $\begin{array}{c}0.1439^{* * *} \\
(0.0343)\end{array}$ & $17.7450(11.8550)$ & 15812.3 \\
\hline Silver & $0.0000(0.0002)$ & $0.0491^{* * *}(0.0021)$ & $\begin{array}{c}0.9441^{* * *} \\
(0.0025)\end{array}$ & $\begin{array}{c}-7.8688^{* * *} \\
(0.1109)\end{array}$ & $\begin{array}{c}0.2446^{* * *} \\
(0.0671)\end{array}$ & $3.4689^{* * *}(1.1158)$ & 13221.1 \\
\hline Brent & $\begin{array}{l}0.0005^{* *} \\
(0.0003)\end{array}$ & $\begin{array}{c}0.0676^{* * *} \\
(0.0033)\end{array}$ & $\begin{array}{c}0.9275^{* * *} \\
(0.0037)\end{array}$ & $\begin{array}{c}-7.1387^{* * *} \\
(0.2075)\end{array}$ & $\begin{array}{c}0.7326^{* * *} \\
(0.1164)\end{array}$ & $\begin{array}{c}1.5349^{* * *} \\
(0.2478)\end{array}$ & 12450.7 \\
\hline WTI & $0.0004(0.0003)$ & $\begin{array}{c}0.0658^{* * *} \\
(0.0032)\end{array}$ & $\begin{array}{c}0.9198^{* * *} \\
(0.0036)\end{array}$ & $-7.3261^{* * *}(0.0771)$ & $1.0272^{* * *}(0.1021)$ & $\begin{array}{c}1.6435^{* * *} \\
(0.1686) \\
\end{array}$ & 11925.6 \\
\hline
\end{tabular}

Note. The bracketed numbers are the standard errors of the estimations. *, **, and ${ }^{* * *}$ denote significance at the $10 \%, 5 \%$, and $1 \%$ levels, respectively. Log $L$ is the logarithmic likelihood of the estimation.

volatilities in crude oil markets even with the simultaneously positive impacts of ID-EMV on them.

Tables 6-9 show the estimation results with both RV and ID-EMV lagged through 3 to 12 months. The revealed empirical findings are highly in line with those presented in Section 4. First of all, most of the parameters estimated are significant, except for several ones of $\omega$ and $w_{1}$, further indicating the nice goodness of fit of GARCH-MIDAS 
TABLE 3: Estimation results of GARCH-MIDAS + ID-EMV models of futures volatility by infectious disease with 6-month lags.

\begin{tabular}{|c|c|c|c|c|c|c|c|}
\hline Futures & $\omega$ & $\alpha$ & $\beta$ & $m$ & $\theta$ & $w$ & $\log L$ \\
\hline Gold & $\begin{array}{c}0.0003^{* *} \\
(0.0001)\end{array}$ & $\begin{array}{c}0.0246^{* * *} \\
(0.0012)\end{array}$ & $\begin{array}{c}0.9753^{* * *} \\
(0.0013)\end{array}$ & $\begin{array}{c}-9.6726^{* * *} \\
(0.2460)\end{array}$ & $\begin{array}{c}1.6900^{* * * *} \\
(0.1358)\end{array}$ & $\begin{array}{c}1.0947^{* * *} \\
(0.0536)\end{array}$ & 15609.7 \\
\hline Silver & $0.0000(0.0002)$ & $0.0319^{* * *}(0.0012)$ & $0.9681^{* * *}(0.0012)$ & $\begin{array}{c}-9.9052^{* * *} \\
(0.3591)\end{array}$ & $\begin{array}{c}1.6535^{* * *} \\
(0.1607)\end{array}$ & $\begin{array}{c}1.0045^{* * *} \\
(0.0373)\end{array}$ & 12996.7 \\
\hline Brent & $\begin{array}{c}0.0005^{* *} \\
(0.0003)\end{array}$ & $\begin{array}{c}0.0690^{* * *} \\
(0.0034)\end{array}$ & $\begin{array}{c}0.9248^{* * *} \\
(0.0040)\end{array}$ & $\begin{array}{c}-7.2990^{* * *} \\
(0.2040)\end{array}$ & $\begin{array}{c}0.6740^{* * *} \\
(0.1748)\end{array}$ & $3.9198^{* * *}(1.2002)$ & 12296.7 \\
\hline WTI & $0.0004^{*}(0.0003)$ & $\begin{array}{c}0.0696^{* * *} \\
(0.0033)\end{array}$ & $\begin{array}{c}0.9146^{* * *} \\
(0.0037)\end{array}$ & $\begin{array}{c}-7.3387^{* * *} \\
(0.0767)\end{array}$ & $\begin{array}{c}1.0803^{* * *} \\
(0.1406)\end{array}$ & $\begin{array}{c}3.4832^{* * * *} \\
(0.5312)\end{array}$ & 11782.4 \\
\hline
\end{tabular}

Note. The bracketed numbers are the standard errors of the estimations. *, ${ }^{* *}$, and ${ }^{* * *}$ denote significance at the $10 \%, 5 \%$, and $1 \%$ levels, respectively. Log $L$ is the logarithmic likelihood of the estimation.

TABLE 4: Estimation results of GARCH-MIDAS + ID-EMV models of futures volatility by infectious disease with 9-month lags.

\begin{tabular}{|c|c|c|c|c|c|c|c|}
\hline Futures & $\omega$ & $\alpha$ & $\beta$ & $m$ & $\theta$ & $w$ & $\log L$ \\
\hline Gold & $\begin{array}{l}0.0003^{* *} \\
(0.0001)\end{array}$ & $\begin{array}{c}0.0327^{* * *} \\
(0.0023)\end{array}$ & $\begin{array}{c}0.9581^{* * *} \\
(0.0030)\end{array}$ & $-9.1116^{* * *}(0.0651)$ & $\begin{array}{c}1.1873^{* * *} \\
(0.2522)\end{array}$ & $2.4184^{* * *}(0.5201)$ & 15397.2 \\
\hline Silver & $0.0000(0.0002)$ & $\begin{array}{c}0.0333^{* * *} \\
(0.0013)\end{array}$ & $\begin{array}{c}0.9667^{* * * *} \\
(0.0013)\end{array}$ & $\begin{array}{c}-9.2487^{* * *} \\
(0.1578)\end{array}$ & $\begin{array}{c}0.9361^{* * *} \\
(0.2638)\end{array}$ & $\begin{array}{c}2.2681^{* * *} \\
(0.6303)\end{array}$ & 12749.8 \\
\hline Brent & $0.0005^{*}(0.0003)$ & $\begin{array}{c}0.0683^{* * *} \\
(0.0035)\end{array}$ & $\begin{array}{c}0.9258^{* * *} \\
(0.0039)\end{array}$ & $\begin{array}{c}-7.2736^{* * *} \\
(0.1853)\end{array}$ & $\begin{array}{c}0.7979^{* * *} \\
(0.2370)\end{array}$ & $5.1022^{* * *}(1.7731)$ & 12146.2 \\
\hline WTI & $0.0005(0.0003)$ & $\begin{array}{c}0.0680^{* * *} \\
(0.0032)\end{array}$ & $\begin{array}{c}0.9155^{* * *} \\
(0.0036)\end{array}$ & $\begin{array}{c}-7.3866^{* * *} \\
(0.0707)\end{array}$ & $1.2215^{* * *}(0.1723)$ & $\begin{array}{c}4.8095^{* * *} \\
(0.8107)\end{array}$ & 11634.6 \\
\hline
\end{tabular}

Note. The bracketed numbers are the standard errors of the estimations. *, ${ }^{* *}$, and ${ }^{* * *}$ denote significance at the $10 \%, 5 \%$, and $1 \%$ levels, respectively. Log $L$ is the logarithmic likelihood of the estimation.

TABLE 5: Estimation results of GARCH-MIDAS + ID-EMV models of futures volatility by infectious disease with 12-month lags.

\begin{tabular}{|c|c|c|c|c|c|c|c|}
\hline Futures & $\omega$ & $\alpha$ & $\beta$ & $m$ & $\theta$ & $w$ & $\log L$ \\
\hline Gold & $0.0003^{* *}(0.001)$ & $\begin{array}{c}0.0339^{* * *} \\
(0.0022)\end{array}$ & $\begin{array}{l}0.9579^{* * *} \\
(0.0030)\end{array}$ & $\begin{array}{c}-9.0390^{* * *} \\
(0.0751)\end{array}$ & $\begin{array}{c}0.5433^{* * *} \\
(0.1477)\end{array}$ & $8.7631^{* *}(3.4253)$ & 15168.9 \\
\hline Silver & $0.0000(0.0002)$ & $\begin{array}{c}0.0347^{* * *} \\
(0.0013)\end{array}$ & $\begin{array}{c}0.9653^{* * *} \\
(0.0013)\end{array}$ & $\begin{array}{c}-9.2016^{* * *} \\
(0.3558)\end{array}$ & $\begin{array}{c}0.2437^{* * * *} \\
(0.0559)\end{array}$ & $\begin{array}{c}18.0210^{* * *} \\
(5.8944)\end{array}$ & 12530.3 \\
\hline Brent & $\begin{array}{l}0.0005^{* *} \\
(0.0003)\end{array}$ & $\begin{array}{c}0.0677^{* * *} \\
(0.0035)\end{array}$ & $\begin{array}{c}0.9255^{* * *} \\
(0.0040)\end{array}$ & $\begin{array}{c}-7.3990^{* * *} \\
(0.1793)\end{array}$ & $\begin{array}{c}0.7788^{* * *} \\
(0.2325)\end{array}$ & $7.2045^{* * *}(2.5398)$ & 11997.8 \\
\hline WTI & $0.0005^{*}(0.0003)$ & $\begin{array}{c}0.0681^{* * *} \\
(0.0032)\end{array}$ & $\begin{array}{c}0.9158^{* * *} \\
(0.0036)\end{array}$ & $\begin{array}{c}-7.3793^{* * *} \\
(0.0731)\end{array}$ & $\begin{array}{c}1.2248^{* * * *} \\
(0.1826)\end{array}$ & $6.5162^{* * *}(1.1766)$ & 11488.7 \\
\hline
\end{tabular}

Note. The bracketed numbers are the standard errors of the estimations. ${ }^{*},{ }^{* *}$, and ${ }^{* * *}$ denote significance at the $10 \%, 5 \%$, and $1 \%$ levels, respectively. Log $L$ is the logarithmic likelihood of the estimation.

models in these commodity futures markets. Secondly, the $\alpha$ and $\beta$ parameters for short-term GARCH $(1,1)$ volatility models are all significant at the $1 \%$ level, also showing notable short-term volatility clustering in these markets. Thirdly, the majority of the estimated $\theta_{1}$ coefficients for lagged RV are significantly negative with few exceptions in gold futures. This result shows that past realized volatility can adversely affect the long-term volatility of the current period. In other words, high (low) realized volatility in commodity futures markets will lead to low (high) permanent volatility in this time. Lastly, the $\theta_{2}$ coefficients for ID-EMV, which we are most concerned about, are all positively significant at the $1 \%$ level, showing high agreement with the previous findings in Tables 2-6. These results reveal that even after controlling the effects of the past realized volatility, the infectious disease epidemic does have positive impacts on the long-run volatility in precious metal and crude oil futures markets. In addition, we also observe that ID-EMV has larger impacts (i.e., larger $\theta_{2}$ ) on the permanent volatility in crude oil markets than it does in precious metal markets. Moreover, the impacts of ID-EMV on gold (WTI oil) is greater than those on silver (Brent oil), which are also highly consistent with the findings in Tables 2-5.

All in all, the empirical outcomes in this section are in excellent conformity with the previous results, providing confirmative evidence that infectious disease does have significant impacts on precious metal and crude oil futures markets, and these effects can last through 3 to 12 months. 

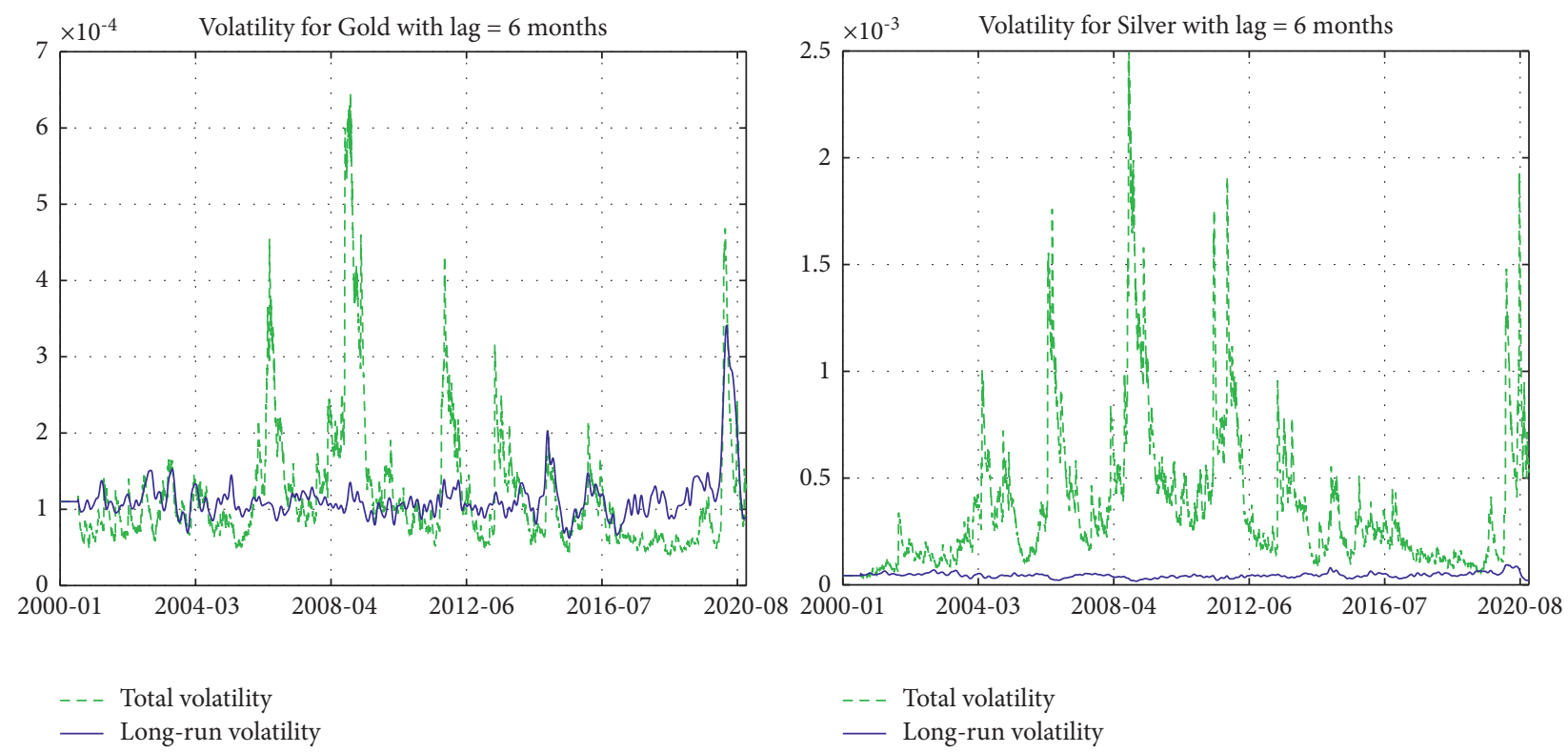

- - - Total volatility

__ Long-run volatility
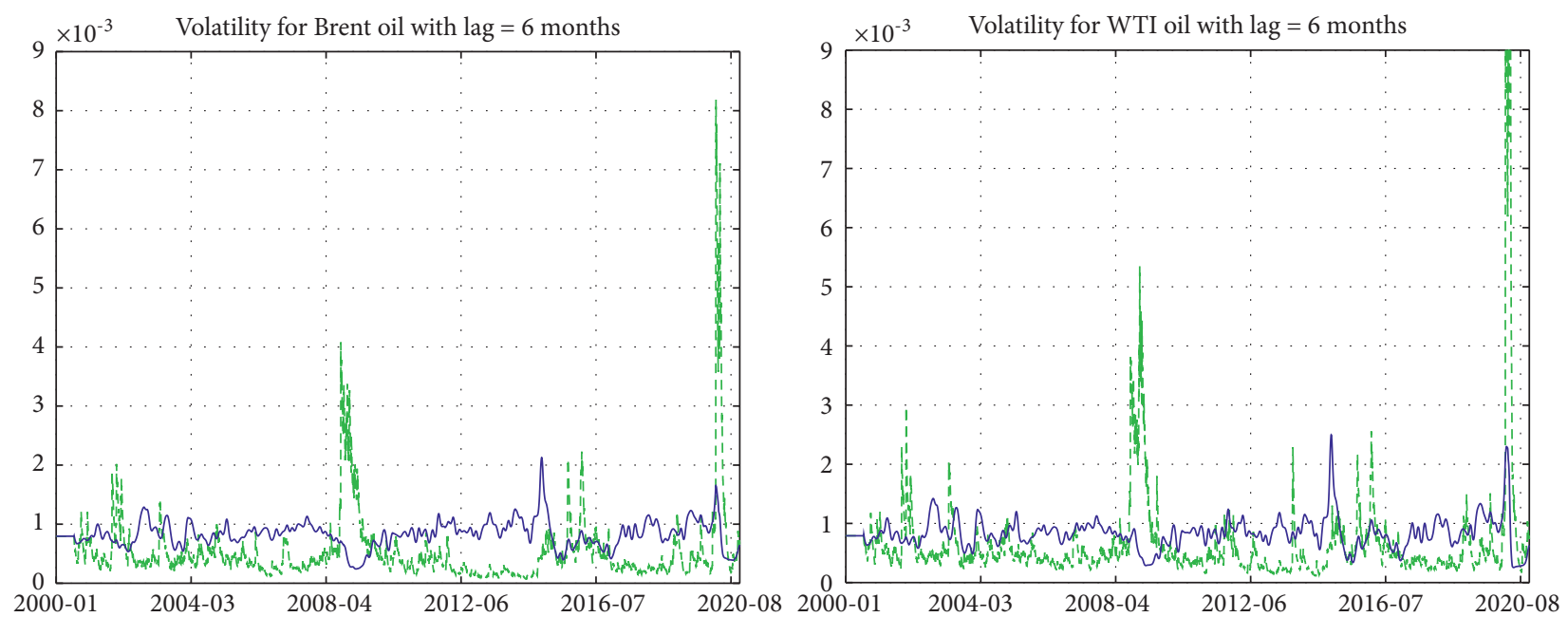

-- - Total volatility
— Long-run volatility

$\begin{array}{ll}\text { _- } & \text { Total volatility } \\ \text { _ } & \text { Long-run volatility }\end{array}$

FIGURE 3: Estimated total and long-run volatility of precious metal and crude oil futures with GARCH-MIDAS + RV + ID-EMV models.

TABLE 6: Estimation results of GARCH-MIDAS + RV + ID-EMV models of futures volatility by infectious disease with 3-month lags.

\begin{tabular}{lccccccccc}
\hline Futures & $\omega$ & $\alpha$ & $\beta$ & $m$ & $\theta_{1}$ & $\theta_{2}$ & $w_{1}$ & $w_{2}$ & $\log L$ \\
\hline \multirow{2}{*}{ Gold } & $0.0003^{* *}$ & $0.0309^{* * *}$ & $0.9609^{* * *}$ & $-9.1269^{* * *}$ & 18.3390 & $0.4661^{* * *}$ & 45.0800 & $2.1536^{* * *}$ & 15848.4 \\
& $(0.0001)$ & $(0.0030)$ & $(0.0041)$ & $(0.0789)$ & $(18.1600)$ & $(0.0861)$ & $(160.7300)$ & $(0.5202)$ & \\
\multirow{2}{*}{ Silver } & 0.0000 & $0.0615^{* * *}$ & $0.9316^{* * *}$ & $-7.619^{* * *}$ & $-24.49^{* * *}$ & $0.2980^{* * *}$ & $6.5012^{* * *}$ & $2.8758^{* * *}$ & 13230.9 \\
& $(0.0002)$ & $(0.0029)$ & $(0.0032)$ & $(0.1416)$ & $(4.8943)$ & $(0.0816)$ & $(1.5580)$ & $(0.8610)$ & \\
\multirow{3}{*}{ Brent } & $0.0001^{* *}$ & $0.0745^{* * *}$ & $0.9207^{* * *}$ & $-7.0141^{* * *}$ & $-5.8417^{* *}$ & $0.8973^{* * *}$ & 18.9300 & $1.4169^{* * *}$ & 12452.3 \\
& $(0.0000)$ & $(0.0040)$ & $(0.0043)$ & $(0.2340)$ & $(2.6558)$ & $(0.1363)$ & $(23.8830)$ & $(0.1946)$ & \\
\multirow{2}{*}{ WTI } & 0.0005 & $0.0638^{* * *}$ & $0.9249^{* * *}$ & $-7.2011^{* * *}$ & $-4.6791^{* * *}$ & $1.0860^{* * *}$ & $1.0010^{* * *}$ & $1.4478^{* * *}$ & 11927.4 \\
& $(0.0003)$ & $(0.0031)$ & $(0.0035)$ & $(0.1006)$ & $(1.7145)$ & $(0.1124)$ & $(0.2983)$ & $(0.1372)$ & \\
\hline
\end{tabular}

Note. The bracketed numbers are the standard errors of the estimations. ${ }^{*},{ }^{* *}$, and ${ }^{* * *}$ denote significance at the $10 \%, 5 \%$, and $1 \%$ levels, respectively. Log $L$ is the logarithmic likelihood of the estimation. 
TABLE 7: Estimation results of GARCH-MIDAS + RV + ID-EMV models of futures volatility by infectious disease with 6-month lags.

\begin{tabular}{|c|c|c|c|c|c|c|c|c|c|}
\hline Futures & $\omega$ & $\alpha$ & $\beta$ & $m$ & $\theta_{1}$ & $\theta_{2}$ & $w_{1}$ & $w_{2}$ & $\log L$ \\
\hline Gold & $\begin{array}{l}0.0003^{* *} \\
(0.0001)\end{array}$ & $\begin{array}{c}0.0296^{* * *} \\
(0.0024)\end{array}$ & $\begin{array}{c}0.9626^{* * *} \\
(0.0031)\end{array}$ & $\begin{array}{c}-9.1429^{* * *} \\
(0.0899)\end{array}$ & $\begin{array}{c}-5.3522 \\
(24.1230)\end{array}$ & $\begin{array}{c}1.6697^{* * *} \\
(0.1654)\end{array}$ & $\begin{array}{c}5.0839 \\
(32.9730)\end{array}$ & $\begin{array}{c}1.1631^{* * *} \\
(0.0718)\end{array}$ & 15632.3 \\
\hline Silver & $\begin{array}{c}0.0000 \\
(0.0002)\end{array}$ & $\begin{array}{c}0.0369^{* * *} \\
(0.0015)\end{array}$ & $\begin{array}{c}0.9631^{* * *} \\
(0.0014)\end{array}$ & $\begin{array}{c}-9.8573^{* * *} \\
(0.4055)\end{array}$ & $\begin{array}{c}-27.9310^{* * *} \\
(6.9849)\end{array}$ & $\begin{array}{c}1.5958^{* * *} \\
(0.1702)\end{array}$ & $\begin{array}{c}2.2015^{* * *} \\
(0.5659)\end{array}$ & $\begin{array}{c}1.0046^{* * *} \\
(0.0398)\end{array}$ & 13003.8 \\
\hline Brent & $\begin{array}{l}0.0005^{* *} \\
(0.0003)\end{array}$ & $\begin{array}{c}0.0648^{* * *} \\
(0.0032)\end{array}$ & $\begin{array}{c}0.9318^{* * *} \\
(0.0034)\end{array}$ & $\begin{array}{c}-6.8889^{* * *} \\
(0.3560)\end{array}$ & $\begin{array}{c}-24.7200^{* * *} \\
(7.9097)\end{array}$ & $\begin{array}{c}1.8309^{* * *} \\
(0.2729)\end{array}$ & $\begin{array}{c}1.5079^{* * *} \\
(0.3790)\end{array}$ & $\begin{array}{c}1.3721^{* * *} \\
(0.1605)\end{array}$ & 12299.1 \\
\hline WTI & $\begin{array}{c}0.0005 \\
(0.0003)\end{array}$ & $\begin{array}{c}0.0672^{* * *} \\
(0.0031)\end{array}$ & $\begin{array}{c}0.9243^{* * *} \\
(0.0031)\end{array}$ & $\begin{array}{c}-6.9706^{* * * *} \\
(0.1545)\end{array}$ & $\begin{array}{c}-14.8170^{* * *} \\
(3.4674)\end{array}$ & $\begin{array}{c}2.2859^{* * *} \\
(0.2242)\end{array}$ & $\begin{array}{c}1.6939^{* * * *} \\
(0.2911)\end{array}$ & $\begin{array}{c}1.4239^{* * * *} \\
(0.1248)\end{array}$ & 11784.9 \\
\hline
\end{tabular}

Note. The bracketed numbers are the standard errors of the estimations. ${ }^{*},{ }^{* *}$, and ${ }^{* * *}$ denote significance at the $10 \%, 5 \%$, and $1 \%$ levels, respectively. Log $L$ is the logarithmic likelihood of the estimation.

TABLE 8: Estimation results of GARCH-MIDAS + RV + ID-EMV models of futures volatility by infectious disease with 9-month lags.

\begin{tabular}{|c|c|c|c|c|c|c|c|c|c|}
\hline Futures & $\omega$ & $\alpha$ & $\beta$ & $m$ & $\theta_{1}$ & $\theta_{2}$ & $w_{1}$ & $w_{2}$ & $\log L$ \\
\hline Gold & $\begin{array}{c}0.0003^{* * *} \\
(0.0001)\end{array}$ & $\begin{array}{c}0.0259^{* * *} \\
(0.0016)\end{array}$ & $\begin{array}{c}0.9741^{* * * *} \\
(0.0018)\end{array}$ & $\begin{array}{c}-9.5552^{* * *} \\
(0.1906)\end{array}$ & $\begin{array}{l}-13.8000 \\
(25.2350)\end{array}$ & $\begin{array}{c}1.4074^{* * *} \\
(0.2258)\end{array}$ & $\begin{array}{c}5.6248 \\
(12.8290)\end{array}$ & $\begin{array}{c}2.3628^{* * * *} \\
(0.3957)\end{array}$ & 15374.3 \\
\hline Silver & $\begin{array}{c}0.0000 \\
(0.0002)\end{array}$ & $\begin{array}{c}0.0403^{* * *} \\
(0.0015)\end{array}$ & $\begin{array}{c}0.9597^{* * *} \\
(0.0015)\end{array}$ & $\begin{array}{c}-9.1283^{* * *} \\
(0.1605)\end{array}$ & $\begin{array}{c}-37.5240^{* * *} \\
(8.9184)\end{array}$ & $\begin{array}{c}0.2559^{* * *} \\
(0.0822)\end{array}$ & $\begin{array}{c}3.1900^{* * *} \\
(0.8631)\end{array}$ & $\begin{array}{l}9.0347^{* *} \\
(3.8279)\end{array}$ & 12756.8 \\
\hline Brent & $\begin{array}{l}0.0005^{*} \\
(0.0003)\end{array}$ & $\begin{array}{c}0.0651^{* * *} \\
(0.0032)\end{array}$ & $\begin{array}{c}0.9318^{* * *} \\
(0.0035)\end{array}$ & $\begin{array}{c}-6.8409^{* * *} \\
(0.3207)\end{array}$ & $\begin{array}{c}-20.6470^{*} \\
(11.3380)\end{array}$ & $\begin{array}{c}1.2633^{* * *} \\
(0.4629)\end{array}$ & $\begin{array}{l}2.2151^{* *} \\
(1.0360)\end{array}$ & $\begin{array}{l}3.2141^{* *} \\
(1.2817)\end{array}$ & 12147.8 \\
\hline WTI & $\begin{array}{c}0.0005 \\
(0.0003) \\
\end{array}$ & $\begin{array}{c}0.0647^{* * *} \\
(0.0030)\end{array}$ & $\begin{array}{c}0.9249^{* * *} \\
(0.0033)\end{array}$ & $\begin{array}{c}-7.1367^{* * *} \\
(0.1473)\end{array}$ & $\begin{array}{c}-11.2310^{* *} \\
(5.0179)\end{array}$ & $\begin{array}{c}1.6444^{* * *} \\
(0.2954)\end{array}$ & $\begin{array}{c}2.3544^{* * *} \\
(0.7674) \\
\end{array}$ & $\begin{array}{c}3.3541^{* * *} \\
(0.6979)\end{array}$ & 11636.3 \\
\hline
\end{tabular}

Note. The bracketed numbers are the standard errors of the estimations. *, ${ }^{* *}$, and ${ }^{* * *}$ denote significance at the $10 \%, 5 \%$, and $1 \%$ levels, respectively. Log $L$ is the logarithmic likelihood of the estimation.

TABLE 9: Estimation results of GARCH-MIDAS + RV + ID-EMV models of futures volatility by infectious disease with 12-month lags.

\begin{tabular}{lccccccccc}
\hline Futures & $\omega$ & $\alpha$ & $\beta$ & $m$ & $\theta_{1}$ & $\theta_{2}$ & $w_{1}$ & $w_{2}$ & $\log L$ \\
\hline \multirow{2}{*}{ Gold } & $0.0003^{* *}$ & $0.0378^{* * *}$ & $0.9540^{* * *}$ & $-8.9224^{* * *}$ & $-60.2300^{* *}$ & $2.0407^{* * *}$ & 11.408 & $2.0497^{* * *}$ & 15171.8 \\
& $(0.0001)$ & $(0.0030)$ & $(0.0035)$ & $(0.1138)$ & $(27.8850)$ & $(0.4188)$ & $(7.8111)$ & $(0.3817)$ & \\
\multirow{2}{*}{ Silver } & 0.0000 & $0.0406^{* * *}$ & 0.9594 & $-9.1784^{* * *}$ & $-37.1680^{* * *}$ & $0.2913^{* * *}$ & $4.5762^{* * *}$ & $12.369^{* * *}$ & 12537.9 \\
& $(0.0002)$ & $(0.0015)$ & $(0.0015)$ & $(0.3925)$ & $(9.3567)$ & $(0.0828)$ & $(1.3800)$ & $(4.6568)$ & \\
\multirow{3}{*}{ Brent } & $0.0005^{* *}$ & $0.0652^{* * *}$ & $0.9301^{* * *}$ & $-7.1647^{* * *}$ & -14.927 & $1.1032^{* * *}$ & 3.2782 & $5.0775^{* *}$ & 11998.7 \\
& $(0.0002)$ & $(0.0003)$ & $(0.0004)$ & $(0.3600)$ & $(13.4370)$ & $(0.4235)$ & $(2.6360)$ & $(2.1906)$ \\
\multirow{2}{*}{ WTI } & 0.0005 & $0.0655^{* * *}$ & $0.9234^{* * *}$ & $-7.1677^{* * *}$ & $-9.9499^{*}$ & $1.6611^{* * *}$ & $3.2375^{* *}$ & $4.5244^{* * *}$ & 11490.1 \\
& $(0.0003)$ & $(0.0031)$ & $(0.0034)$ & $(0.1528)$ & $(5.4216)$ & $(0.3340)$ & $(1.3331)$ & $(1.0596)$ & 1 \\
\hline
\end{tabular}

Note. The bracketed numbers are the standard errors of the estimations. * , **, and ${ }^{* * *}$ denote significance at the $10 \%, 5 \%$, and $1 \%$ levels, respectively. Log $L$ is the logarithmic likelihood of the estimation.

\section{Conclusions}

Commodity futures markets are sensitive to many kinds of impacts, such as supply-demand shocks, geopolitical uncertainty, speculation surges, and public health emergencies. Especially, in the undergoing COVID-19 epidemic, commodity futures markets have experienced mind-bogglingly large swings and brought many troubles to policy makers, commodity productors and demanders, and investors. Therefore, this paper focuses on quantifying the impacts of the infectious disease epidemic on the permanent volatility of two import commodity futures, i.e., precious metal and crude oil.

The major empirical results show that the infectious disease epidemic does have positive impacts on the long-run volatilities of gold, silver, Brent, and WTI crude oil futures, and these effects can last from short term (3 months) to relative long term (12 months). Additionally, the influences of the infectious disease epidemic on crude oil futures are greater than those on precious metal for the reason that the former is innately tasked to be risk assets due to its tight relationships with industry and agriculture production, as well as transportation industry. Furthermore, we find that the infectious disease pandemic has larger impacts on gold (WTI oil) futures than that on silver (Brent oil) futures. All these findings are robust after controlling the effects of their own lagged realized volatilities.

The empirical results in this paper have several important policy and economic implications: firstly, infectious disease epidemic is recognized as a significant risk factor for commodity futures markets in this paper. Thus, policy makers should give it enough weight when making tailored regulatory policies in futures markets to avoid huge price volatilities and to stabilize market confidence. We also find 
that these positive impacts of ID-EMV on commodity futures can last significantly as long as 12 months. In the consequence, policy makers should not withdraw their fiscal or monetary policies quickly in case it fails to meet their desired goals. Then, for commodity productors and demanders, they must pay keen attention to the trends of infectious disease epidemics and arrange raw material reserves, logistics scheduling, and production plans accordingly, which can enhance the security in their supply chain and capital chain effectively. Last, for investors in commodity futures markets, they have to know that long-run volatility in crude oil futures is easily affected by the infectious disease epidemic than precious futures. Therefore, they can tailor the risk exposure of their portfolio by rebalancing the weights in precious metal and oil assets during a pandemic. In addition, this paper shows that the impacts of ID-EMV on gold (WTI oil) are greater than those on silver (Brent oil). This result offers investors with options on different precious metal and crude oil assets to hedge the market risks stemming from the infectious disease epidemic. For investors, gold may be a better choice than silver to hedge the market risks in holding WTI crude oil, while silver is superior to gold in offsetting risks in Brent oil positions.

\section{Data Availability}

The precious metal and crude oil futures price is available at the Wind database, and the ID-EMV data are collected from the website http://www.policyuncertainty.com/ infectious_EMV.html.

\section{Conflicts of Interest}

The authors declare no conflicts of interest.

\section{Authors' Contributions}

Y. S. proposed the original writing idea and finished the introduction section. X.-D. C. finished the empirical estimations and analyses of this paper. Y.-F. Z. prepared the methodology part. Y. W. supervised the writing process of this paper.

\section{Acknowledgments}

This study was funded by the National Natural Science Foundation of China (71671145 and 71971191), Humanities and Social Science Fund of Ministry of Education of China (17YJA790015, 17XJA790002, 18YJC790132, and 18XJA790002), Science and Technology Innovation Team of Yunnan Provincial Universities (2019014), and Yunnan Fundamental Research Projects (202001AS070018).

\section{References}

[1] M. Ali, N. Alam, and S. A. R. Rizvi, "Coronavirus (COVID19) - an epidemic or pandemic for financial markets," Journal of Behavioral and Experimental Finance, vol. 27, Article ID 100341, 2020.
[2] A. B. Amar, F. Belaid, A. B. Youssef, B. Chiao, and K. Guesmi, "The unprecedented reaction of equity and commodity markets to COVID-19," Finance Research Letters, vol. 38, Article ID 101853, 2020.

[3] E. Bouri, O. Cepni, D. Gabauer, and R. Gupta, "Return connectedness across asset classes around the COVID-19 outbreak," International Review of Financial Analysis, vol. 73, Article ID 101646, 2020.

[4] S. Corbet, Y. Hou, Y. Hu, L. Oxley, and D. Xu, "Pandemicrelated financial market volatility spillovers: evidence from the Chinese COVID-19 epicentre," International Review of Economics \& Finance, vol. 71, pp. 55-81, 2021.

[5] S. Corbet, C. Larkin, and B. Lucey, "The contagion effects of the COVID-19 pandemic: evidence from gold and cryptocurrencies," Finance Research Letters, vol. 35, Article ID 101554, 2020.

[6] A. P. Fassas, "Risk aversion connectedness in developed and emerging equity markets before and after the COVID-19 pandemic," Heliyon, vol. 6, no. 12, Article ID e05715, 2020.

[7] C. Gharib, S. Mefteh-Wali, and S. B. Jabeur, "The bubble contagion effect of COVID-19 outbreak: evidence from crude oil and gold markets," Finance Research Letters, vol. 38, Article ID 101703, 2020.

[8] S. Gunay, "Comparing COVID-19 with the GFC: a shockwave analysis of currency markets," Research in International Business and Finance, vol. 56, Article ID 101377, 2021.

[9] N. Iqbal, Z. Fareed, G. Wan, and F. Shahzad, "Asymmetric nexus between COVID-19 outbreak in the world and cryptocurrency market," International Review of Financial Analysis, vol. 73, Article ID 101613, 2021.

[10] T. H. Le, H. X. Do, D. K. Nguyen, and A. Sensoy, "Covid-19 pandemic and tail-dependency networks of financial assets," Finance Research Letters, vol. 38, Article ID 101800, 2020.

[11] N. Norouzi, G. Zarazua de Rubens, S. Choupanpiesheh, and P. Enevoldsen, "When pandemics impact economies and climate change: exploring the impacts of COVID-19 on oil and electricity demand in China," Energy Research \& Social Science, vol. 68, Article ID 101654, 2020.

[12] M. Omane-Adjepong and I. P. Alagidede, "Exploration of safe havens for Africa's stock markets: a test case under COVID-19 crisis," Finance Research Letters, vol. 38, Article ID 101877, 2020.

[13] J. Sadefo Kamdem, R. Bandolo Essomba, and J. Njong Berinyuy, "Deep learning models for forecasting and analyzing the implications of COVID-19 spread on some commodities markets volatilities," Chaos, Solitons \& Fractals, vol. 140, Article ID 110215, 2020.

[14] Y. Sakurai and T. Kurosaki, "How has the relationship between oil and the US stock market changed after the COVID19 crisis?" Finance Research Letters, vol. 37, Article ID 101773, 2020.

[15] A. H. Samadi, S. Owjimehr, and Z. Nezhad Halafi, "The crossimpact between financial markets, Covid-19 pandemic, and economic sanctions: the case of Iran," Journal of Policy Modeling, vol. 43, pp. 34-55, 2020.

[16] A. Sharif, C. Aloui, and L. Yarovaya, "COVID-19 pandemic, oil prices, stock market, geopolitical risk and policy uncertainty nexus in the US economy: fresh evidence from the wavelet-based approach," International Review of Financial Analysis, vol. 70, Article ID 101496, 2020.

[17] J. Wang and X. Wang, "COVID-19 and financial market efficiency: evidence from an entropy-based analysis," Finance Research Letters, Article ID 101888, 2021. 
[18] O. B. Adekoya, J. A. Oliyide, and G. O. Oduyemi, "How COVID-19 upturns the hedging potentials of gold against oil and stock markets risks: nonlinear evidences through threshold regression and Markov-regime switching models," Resources Policy, vol. 70, Article ID 101926, 2020.

[19] A. Dutta, D. Das, R. K. Jana, and X. V. Vo, "COVID-19 and oil market crash: revisiting the safe haven property of gold and bitcoin," Resources Policy, vol. 69, Article ID 101816, 2020.

[20] W. Mensi, A. Sensoy, X. V. Vo, and S. H. Kang, "Impact of COVID-19 outbreak on asymmetric multifractality of gold and oil prices," Resources Policy, vol. 69, Article ID 101829, 2020.

[21] A. A. Salisu, X. V. Vo, and A. Lawal, "Hedging oil price risk with gold during COVID-19 pandemic," Resources Policy, vol. 70, Article ID 101897, 2020.

[22] P. Li and Z. Dong, "Time-varying network analysis of fluctuations between crude oil and Chinese and U.S. gold prices in different periods," Resources Policy, vol. 68, Article ID 101749, 2020.

[23] K. Mokni, S. Hammoudeh, A. N. Ajmi, and M. Youssef, "Does economic policy uncertainty drive the dynamic connectedness between oil price shocks and gold price?" Resources Policy, vol. 69, Article ID 101819, 2020.

[24] K. Morema and L. Bonga-Bonga, "The impact of oil and gold price fluctuations on the South African equity market: volatility spillovers and financial policy implications," Resources Policy, vol. 68, Article ID 101740, 2020.

[25] A. A. Salisu and I. Adediran, "Gold as a hedge against oil shocks: evidence from new datasets for oil shocks," Resources Policy, vol. 66, Article ID 101606, 2020.

[26] K. H. Al-Yahyaee, W. Mensi, A. Sensoy, and S. H. Kang, "Energy, precious metals, and GCC stock markets: is there any risk spillover?" Pacific-Basin Finance Journal, vol. 56, pp. 45-70, 2019.

[27] K. H. Al-Yahyaee, M. U. Rehman, I. M. Wanas Al-Jarrah, W. Mensi, and X. V. Vo, "Co-movements and spillovers between prices of precious metals and non-ferrous metals: a multiscale analysis," Resources Policy, vol. 67, Article ID 101680, 2020.

[28] M. Balcilar and Z. A. Ozdemir, "The volatility effect on precious metals price returns in a stochastic volatility in mean model with time-varying parameters," Physica A: Statistical Mechanics and Its Applications, vol. 534, Article ID 122329, 2019.

[29] K. Guhathakurta, S. R. Dash, and D. Maitra, "Period specific volatility spillover based connectedness between oil and other commodity prices and their portfolio implications," Energy Economics, vol. 85, Article ID 104566, 2020.

[30] L. Hau, H. Zhu, R. Huang, and X. Ma, "Heterogeneous dependence between crude oil price volatility and China's agriculture commodity futures: evidence from quantile-onquantile regression," Energy, vol. 213, Article ID 118781, 2020.

[31] H. Hu, D. Chen, B. Sui, L. Zhang, and Y. Wang, "Price volatility spillovers between supply chain and innovation of financial pledges in China," Economic Modelling, vol. 89, pp. 397-413, 2020.

[32] S. Husain, A. K. Tiwari, K. Sohag, and M. Shahbaz, "Connectedness among crude oil prices, stock index and metal prices: an application of network approach in the USA," Resources Policy, vol. 62, pp. 57-65, 2019.

[33] Y. Jiang, Y. Fu, and W. Ruan, "Risk spillovers and portfolio management between precious metal and BRICS stock markets," Physica A: Statistical Mechanics and Its Applications, vol. 534, Article ID 120993, 2019.
[34] M. C. K. Lau, S. A. Vigne, S. Wang, and L. Yarovaya, "Return spillovers between white precious metal ETFs: the role of oil, gold, and global equity," International Review of Financial Analysis, vol. 52, pp. 316-332, 2017.

[35] Y. Li, J. Huang, and J. Chen, "Dynamic spillovers of geopolitical risks and gold prices: new evidence from 18 emerging economies," Resources Policy, vol. 70, Article ID 101938, 2021.

[36] T. Liu and X. Gong, "Analyzing time-varying volatility spillovers between the crude oil markets using a new method," Energy Economics, vol. 87, Article ID 104711, 2020.

[37] W. Mensi, K. H. Al-Yahyaee, and S. Hoon Kang, "Timevarying volatility spillovers between stock and precious metal markets with portfolio implications," Resources Policy, vol. 53, pp. 88-102, 2017.

[38] W. Mensi, S. Hammoudeh, M. U. Rehman, A. A. S. AlMaadid, and S. Hoon Kang, "Dynamic risk spillovers and portfolio risk management between precious metals and global foreign exchange markets," The North American Journal of Economics and Finance, vol. 51, Article ID 101086, 2020.

[39] W. Mensi, J. A. Hernandez, S. M. Yoon, X. V. Vo, and S. H. Kang, "Spillovers and connectedness between major precious metals and major currency markets: the role of frequency factor," International Review of Financial Analysis, vol. 74, Article ID 101672, 2021.

[40] W. Mensi, M. U. Rehman, and X. V. Vo, "Spillovers and comovements between precious metals and energy markets: implications on portfolio management," Resources Policy, vol. 69, Article ID 101836, 2020.

[41] W. Mensi, A. Sensoy, A. Aslan, and S. H. Kang, "High-frequency asymmetric volatility connectedness between Bitcoin and major precious metals markets," The North American Journal of Economics and Finance, vol. 50, Article ID 101031, 2019.

[42] J. C. Reboredo and A. Ugolini, "Price spillovers between rare earth stocks and financial markets," Resources Policy, vol. 66, Article ID 101647, 2020.

[43] M. U. Rehman, "Do bitcoin and precious metals do any good together? An extreme dependence and risk spillover analysis," Resources Policy, vol. 68, Article ID 101737, 2020.

[44] S. J. H. Shahzad, M. U. Rehman, and R. Jammazi, "Spillovers from oil to precious metals: quantile approaches," Resources Policy, vol. 61, pp. 508-521, 2019.

[45] A. K. Tiwari, B. R. Mishra, and S. A. Solarin, "Analysing the spillovers between crude oil prices, stock prices and metal prices: the importance of frequency domain in USA," Energy, vol. 220, Article ID 119732, 2021.

[46] G. S. Uddin, J. A. Hernandez, S. J. H. Shahzad, and S. H. Kang, "Characteristics of spillovers between the US stock market and precious metals and oil," Resources Policy, vol. 66, Article ID 101601, 2020.

[47] G. S. Uddin, S. J. H. Shahzad, G. Boako, J. A. Hernandez, and B. M. Lucey, "Heterogeneous interconnections between precious metals: evidence from asymmetric and frequencydomain spillover analysis," Resources Policy, vol. 64, Article ID 101509, 2019.

[48] D. C. Yildirim, E. I. Cevik, and O. Esen, "Time-varying volatility spillovers between oil prices and precious metal prices," Resources Policy, vol. 68, Article ID 101783, 2020.

[49] C. Zhang, X. Shi, and D. Yu, "The effect of global oil price shocks on China's precious metals market: a comparative analysis of gold and platinum," Journal of Cleaner Production, vol. 186, pp. 652-661, 2018. 
[50] F. X. Diebold and K. Yilmaz, "Better to give than to receive: predictive directional measurement of volatility spillovers," International Journal of Forecasting, vol. 28, no. 1, pp. 57-66, 2012.

[51] R. Seyedeh Fatemeh, B. Mehdi, B. Bahareh Ramezanian, and S. M. J. Razmi, "The impact of US monetary policy uncertainties on oil and gas return volatility in the futures and spot markets," Journal of Petroleum Science and Engineering, vol. 191, Article ID 107232, 2020.

[52] Y. Wei, S. Qin, X. Li, S. Zhu, and G. Wei, "Oil price fluctuation, stock market and macroeconomic fundamentals: evidence from China before and after the financial crisis," Finance Research Letters, vol. 30, pp. 23-29, 2019.

[53] Y. Zhang, Y. Wei, Y. Zhang, and D. Jin, "Forecasting oil price volatility: forecast combination versus shrinkage method," Energy Economics, vol. 80, pp. 423-433, 2019.

[54] R. F. Engle and J. G. Rangel, "The spline-GARCH model for low-frequency volatility and its global macroeconomic causes," Review of Financial Studies, vol. 21, no. 3, pp. 1187-1222, 2008.

[55] R. F. Engle, E. Ghysels, and B. Sohn, "Stock market volatility and macroeconomic fundamentals," Review of Economics and Statistics, vol. 95, no. 3, pp. 776-797, 2013.

[56] F. Corsi, "A simple approximate long-memory model of realized volatility," Journal of Financial Econometrics, vol. 7, pp. 174-196, 2009.

[57] S. Baker, B. Nicholas, J. D. Steven, K. Kyle, S. Marco, and V. Tasaneeya, "The unprecedented stock market reaction to COVID-19," Covid Economics: Vetted and Real-Time Papers, vol. 1, 2020.

[58] A. K. Pradhan, B. R. Mishra, A. K. Tiwari, and S. Hammoudeh, "Macroeconomic factors and frequency domain causality between gold and silver returns in India," Resources Policy, vol. 68, Article ID 101744, 2020.

[59] T. L. D. Huynh, M. A. Nasir, V. X. Vo, and T. T. Nguyen, "'Small things matter most": the spillover effects in the cryptocurrency market and gold as a silver bullet," North American Journal of Economics \& Finance, vol. 54, Article ID 101277, 2020.

[60] L. Bai, Y. Wei, G. Wei, X. Li, and S. Zhang, "Infectious disease pandemic and permanent volatility of international stock markets: a long-term perspective," Finance Research Letters, vol. 40, Article ID 101709, 2021. 